\title{
Managing Employee Attention and Internal Branding
}

\begin{abstract}
We extend the marketing literature on internal branding by developing a theoretical framework to explain the processes whereby brand orientation affects in- and extra-role employee brand-building behavior from the theoretical perspective of the attention-based view. The results of a survey of 314 UK-based nonprofit organizations show that brand orientation leads to the development of internal branding mechanisms, which in turn fosters in-role employee brand-building behaviors. We also find that internal branding mechanisms mediate the effects of brand orientation on extra-role employee brand-building behavior, as there exists an inverted U-shaped relationship between internal branding mechanisms and extra-role employee brand-building behaviors. Furthermore, our result shows that the inverted U-shaped relationship between internal branding mechanisms and extra-role employee brand-building behaviors flips to a concave upward curve when strong interfunctional communications exist.
\end{abstract}

Keywords: Internal branding; Brand orientation; Employee brand-building behaviors; Attention-based view; Inter-functional communications; Nonprofit Organizations 


\section{Introduction}

Internal branding refers to brand-building efforts that focus on promoting a brand inside an organization to motive the employees to transform the brand promise ${ }^{1}$ into reality (Punjaisri, Evanschitzky, \& Wilson, 2009; Vallaster \& de Chernatony, 2006). Increasingly, organizations both in the US and worldwide (Caterpillar, Southwest Airline, etc.) are investing significant resources in internal branding (Baumgarth \& Schmidt, 2010; Punjaisri et al., 2009). For example, a recent study by the Canadian Marketing Association shows that less than $75 \%$ of front line employees encountered internal branding related initiatives in 2000, compared to over 90\% in 2010 (McQuillan \& Oddie, 2011). The objective of this research is to deepen our understanding of how internal branding influences employees’ contributions to their organizations’ brand-building efforts.

To implement internal branding, organizations must build their employees’ knowledge of the brand promise, and scholars highlight the important role that brand orientation (e.g. Baumgarth \& Schmidt, 2010; Urde, Baumgarth, \& Merrilees, 2013) and internal branding mechanisms (IBM) (e.g. Mitchell, 2002; Punjaisri \& Wilson, 2007) play here. Brand orientation refers to organizations' focus on building and sustaining their brand promise (Ewing \& Napoli, 2005; Napoli, 2006). For example, King, So, and Grace (2013) find that foreign hotels in China implement brand orientation by ensuring that the hotel service quality matches their customer's concept of the brand promise. IBM refer to concrete internal communication and training activities to build their employees' awareness and understanding of the brand promise (Mitchell, 2002; Vallaster \& de Chernatony, 2006). For example, Punjaisri and Wilson (2011) study the IBM of Thailand's hotel industry and

\footnotetext{
${ }^{1}$ Brand promise defines as an explicit promise of benefits between an organization and its key stakeholder group, which organization conveys through its public messages (Morhart, Herzog, \& Tomczak, 2009; Punjaisri \& Wilson, 2011). For example, Southwest Airline's brand promise is the highest quality of customer service "positively outrageous service” (Miles \& Mangold, 2005).
} 
identify a range of activities (daily briefings, newsletters, etc.) related to internal brand promise communication. Although some scholars have implied that brand orientation can support the IBM development (e.g. Hankinson, 2001; Urde, 1999), none have used empirical data to examine this. Such insight is critical for organizations to engage in internal branding. Internal branding entails employees transforming the brand promise into reality, which helps to shape customers’ perceptions about the organization’s brand (Miles \& Mangold, 2005). Prior studies call this concept of employees’ actions determining customers' brand promise perceptions “employee brand-building behaviors” (EBBB), which enhance an organization's brand-building efforts (King et al., 2013; Morhart et al., 2009). There are two types of EBBB: in- and extra-role $\mathrm{EBBB}^{2}$. In-role EBBB occurs when employees meet the standard prescribed by their organizational role as brand representatives ${ }^{3}$ (Morhart et al., 2009). For example, Miles and Mangold (2005) suggest that Southwest Airlines employees treat their customers with warmth, respect, and responsiveness in line with their company’s brand promise of a "positively outrageous service”. Extra-role EBBB occurs when employees go beyond their prescribed role of acting according to the brand promise when interacting with customers for the good of the organization’s brand (Miles \& Mangold, 2004; Morhart et al., 2009). For example, Spector and McCarthy (2012) suggest that Nordstrom employees often report doing whatever it takes to serve customers and sharing their experience with their colleagues to improve the customer brand experience. Previous studies on internal branding tend to treat in- and extra-role EBBB as similar (e.g. Baumgarth \& Schmidt, 2010; King \& Grace, 2010), and it remains unclear whether IBM has differential

\footnotetext{
${ }^{2}$ The in- and extra-role performance concept originated in the management literature (e.g. Bateman \& Organ, 1983) to describe two types of work behaviors: 1) those related to a formal job role (in-role performance) and 2) those that exceed the formal job role (extra-role performance). In this study, we follow the suggestion of previous scholars to use the in-/extra-role performance concept to describe employees behaviors that contribute to organizations' brand-building efforts (e.g. Morhart et al., 2009).

${ }^{3}$ Brand representatives are individuals who behave consistently with the brand promise when interacting with customers (Morhart et al., 2009).
} 
effects on in-and extra-role EBBB. Clarifying this might help managers who are in charge of implementing internal brand mechanisms to promote EBBB.

Furthermore, prior studies show that work environments induced by specific factors (i.e. autonomy) can influence employees' attitudes towards supporting their organizations' internal branding efforts (e.g. Punjaisri \& Wilson, 2007; Vallaster \& de Chernatony, 2006). Interfunctional communication takes place between employees in different functional departments (Hulland, Nenkov, \& Barclay, 2012). Therefore, a high degree of interfunctional communication creates a high quality, effective work environment (Fisher, Maltz, \& Jaworski, 1997; Hulland et al., 2012), which may in turn influence the internal branding. For example, Rouziès, Anderson, Kohli, Michaels, Weitz, and Zoltners (2005) suggest that effective communication between employees from the sales and marketing departments leads to salesmarketing integration, enables the marketing-staff to convey the brand promise, and help the salespeople to close orders and treat customers according to the brand promise. However, no studies, to the best of our knowledge, have examined exactly how an interfunctional communication-induced work environment affects internal branding. Such insight helps managers to improve internal branding implementation.

To address these research gaps, we apply the insights of the attention-based view that argues that an organization's decision-makers' behaviors depend on where they focus their attention, so the organization can establish strategic priorities to regulate this (Ocasio, 1997) to develop our theoretical framework (see Figure 1). We test our theoretical framework by analyzing data collected from 314 UK-based nonprofit organizations. Our results make several important contributions. First, our study extends the internal branding literature (e.g. Ewing \& Napoli, 2005; Urde, 1999) by explaining how an organization’s focus on building and sustaining its brand promise affects their concrete communication activities to promote the brand promise internally. Second, we add to the internal branding literature (e.g. 
Baumgarth \& Schmidt, 2010; King \& Grace, 2010) by examining the differential effects of IBM on promoting the in- and extra-role EBBB. Thirdly, by considering interfunctional communication as pivotal in influencing the impacts of IBM on EBBB, our study adds to the internal branding literature by examining the effect of an unexplored work environment on internal branding (e.g. Punjaisri \& Wilson, 2007; Vallaster \& de Chernatony, 2006).

“Insert Figure 1 about Here”

\section{Theory and Hypotheses}

\subsection{Attention-based View of Internal Branding}

The attention-based view describes how organizations regulate and distribute the decision-makers' attention, which consists of three major components: “decision-makers”, “procedural and communication channels” and “attention structures” (Barnett, 2008; Ocasio, 1997). Decision-makers are individuals within an organization who make decisions about performing certain tasks (i.e. customer service) at their discretion. Procedural and communication channels include various administrative procedures (i.e. personnel evaluation) and communication activities (i.e. company newsletters) set up by the organizations. Attention structures are contextual factors (i.e. organizational culture) that reflect organizations' strategic priorities. According to the attention-based view, decision-makers behave according to where they focus their attention, which can be influenced by the organizations’ procedural and communication channels (Barnett, 2008; Ocasio, 1997). For example, employees are more likely to focus on providing high quality service to customers when the organizations emphasize the importance of customer service in their communications to their employees (Baker, Rapp, Meyer, \& Mullins, 2014; King et al., 2013). Furthermore, attention structures provide a context for guiding organizations’ procedural and communication channels development. For example, organizations with a 
strong innovative culture (that consider innovation a strategic priority) are more likely to design administrative procedures and communication activities with a strong emphasis on encouraging innovation activities (Chatman \& Jehn, 1994). In this study, we apply the attention-based view to explain the relationships among brand orientation, IBM, and in- and extra-role EBBB.

Effective internal branding involves employees making conscious decisions to focus on transforming the brand promise into reality when interacting with customers (Baker et al., 2014; Morhart et al., 2009). According to the attention-based view, employees are decisionmakers regarding the internal branding. EBBB reflects the employees' role as decisionmakers who choose to support the organizations' brand-building efforts (Miles \& Mangold, 2004; Morhart et al., 2009). Meanwhile, the procedural and communication channels represent various administrative procedures and communication activities that the organizations set up to influence the decision-makers (Barnett, 2008; Ocasio, 1997). IBM is organizations’ procedural and communication channels, according to the attention-based view, because IBM includes both "internal communication tools” and "training programs" (Punjaisri \& Wilson, 2011), which reflect “communication activities" and "administrative procedures” (respectively), based on the procedural and communication channels concept. Organizations set up IBM to focus their employees’ attention on the brand (e.g. Mitchell, 2002; Papasolomou \& Vrontis, 2006). According to the attention-based view, organizations' procedural and communication channels influence the decision-makers' attention focus (Ocasio, 1997). Following this logic, we propose a relationship between IBM and in- and extra-role EBBB.

We expect the relationship between IBM and in-role EBBB. IBM focuses on using various internal communication tools to instruct employees about the brand promise (Punjaisri et al., 2009; Punjaisri \& Wilson, 2011). When organizations deliver strong, 
consistent information about the brand promise via their internal communication channels, they influence their employees’ attention toward delivering brand promise. Therefore, employees are more likely to become brand representatives and treat customers in a way that is consistent with the brand promise (Punjaisri \& Wilson, 2007).

Hypothesis 1: Internal branding mechanisms have a positive effect on in-role the employee brand-building behaviors.

We expect the relationship between IBM and extra-role EBBB. To encourage extrarole EBBB, organizations need to find ways to increase their employees’ attention level significantly. This means that it is insufficient for organizations merely to disseminate consistent messages about their brand promise to their employees (Hankinson, 2001; Papasolomou \& Vrontis, 2006). IBMs enables organizations both to engage in internal communication and also to provide additional training and orientation programs to enhance their employees’ understanding and awareness of the brand promise (Punjaisri \& Wilson, 2011). The literature suggests that employees can develop deeper emotional connections with the brand through participating in these additional activities (Papasolomou \& Vrontis, 2006). Thus, employees are more likely to support organizations’ brand-building efforts beyond their job context, when organizations implement IBM.

However, the positive effects of IBM on extra-role EBBB decline when IBM become too effective. This is because highly effective IBM can create a strong brand community ${ }^{4}$ within the organization (Morhart et al., 2009), which allows individuals (i.e. employees) to define themselves in terms of both who they are and who they are not (Hickman \& Ward, 2007; Muniz \& Schau, 2005). When a strong brand community exists within an organization, employees are more likely to conform to the set of activities advocated by the organization for brand promise delivery via IBM. They are also less likely to perform activities that the

\footnotetext{
${ }^{4}$ A brand community shares an attachment to a specific brand (Hickman \& Ward, 2007; Morhart et al., 2009). Individuals within the brand community share consciousness, rituals and traditions, and have a sense of "us" (individuals inside the brand community) versus "them (individuals outside the brand community)" (Muniz \& Schau, 2005).
} 
organization does not advocate via IBM, due to their sense of moral responsibility to the brand and fellow participants (i.e. peer employees) in the brand community (Escalas \& Bettman, 2005; Muniz \& Schau, 2005). However, to perform extra-role EBBB, employees need to go beyond their prescribed roles and find other positive ways to deliver the brand promise (Morhart et al., 2009). Therefore, employees are less likely to engage in extra-role EBBB when a strong brand community exists within the firm due to IBM's effectiveness. In other words, when IBM is too effective, it discourages extra-role EBBB.

Hypothesis 2: Internal branding mechanisms have an inverted $U$-shaped effect on extra-role employee brand-building behaviors.

Furthermore, we propose a positive relationship between brand orientation and IBM. Attention structures are the contextual factors within the organization that influence the focus of the organization toward specific strategic priorities (Barnett, 2008). Brand orientation, which represents an organization's focus on building and sustaining the brand promise (Ewing \& Napoli, 2005; Napoli, 2006), is an attention structure, according to the attentionbased view. An organization's adoption of brand orientation should lead to it engaging in three dimensions of brand-building efforts: orchestration, interaction and affect (Ewing \& Napoli, 2005; Napoli, 2006). Building on the attention-based view logic, that highlights the relationship between attention structures and procedural and communication channels, we argue that each of these dimensions of brand-building efforts provide a context for guiding IBM development.

According to Punjaisri and Wilson (2011), IBM comprise two major groups of activities: internal communication, and training. Orchestration reflects organizations' focus on organizing and implementing integrated marketing activities (Napoli, 2006).

Organizations with a high degree of orchestration are more likely to create an environment that allows effective IBM development. It is because that they are more capable of ensuring that all of the tools (i.e. newsletters) used in internal communications or training materials 
deliver consistent brand promise information to the employees. Interaction, on the other hand, reflects to the organizations' focus on establishing a dialogue with the key stakeholders (i.e. employees) (Ewing \& Napoli, 2005). Organizations that engage in a high degree of interaction can constantly refine and improve their IBM. It is because that they can gather feedbacks (via dialogue) from their employees and use it to improve their internal communications and training programs (Papasolomou \& Vrontis, 2006). Finally, affect reflects to organizations' focus on understanding their stakeholders' (i.e. employees) likes/dislikes about the brand (Ewing \& Napoli, 2005; Napoli, 2006). We argue that organizations with a high degree of affect are better able to design effective IBM to capture their employees’ attention, for two reasons. First, these organizations have a better understanding of their employees’ preferences regarding the brand promises (Liu, Chapleo, Ko, \& Ngugi, 2015). Second, they are more capable of predicting their employees’ attitudes towards the brand (Papasolomou \& Vrontis, 2006). In summary, the three brand orientation dimensions guide IBM development.

Hypothesis 3: Brand orientation has a positive effect on internal branding mechanisms.

\subsection{Moderating Effects of Inter-Functional Communication}

The attention-based view also infers that organizational environment (both external i.e. government law, and internal - i.e. organizational culture) influence attention processes (Ocasio, 1997). Interfunctional communication can create an internal (work) environment with high quality, effective inter-employee communication (Hulland et al., 2012). We predict that interfunctional communication enhances the effects of IBM on in-role EBBB. First, IBM requires input from both the marketing and human resource management functions (Hankinson, 2001; Papasolomou \& Vrontis, 2006). Greater interfunctional communication makes marketing and human resources functions’ employees more likely to share ideas and 
understand each other's concerns. Therefore, organizations are better able to design effective IBM to persuade their employees to become brand representatives, when the level of interfunctional communication is high. Second, when organizations disseminate their brand promise to their employees using IBM, certain employees may not feel drawn toward becoming brand representatives (Burmann \& Zeplin, 2005; Punjaisri \& Wilson, 2007). Greater interfunctional communication can create a work environment that enables everyone to share what they have learned about the brand promise via IBM. Thus, employees will be more likely to devote attention toward treating customers in a way that is consistent with the brand promise. In summary, we predict:

Hypothesis 4: Interfunctional communication strengthens the relationship between internal branding mechanisms and in-role employee brand-building behaviors.

Interfunctional communication also plays an important role in facilitating the relationship between IBM and extra-role EBBB. In particular, we posit that interfunctional communicate weakens the positive effects of IBM, when IBM exists at a relatively low level. This is because the communication channels for building employees' understanding about the brand promise remain under-developed at this point (Punjaisri et al., 2009). Under this circumstance, greater interfunctional communication only encourages employees to share with each other their own versions (with personal bias) of the brand promise. This can cause employees to feel confused about the brand promise information they obtain from their organization (via IBM) and the information that they obtain from their colleagues (Miles \& Mangold, 2005). This means that the impact of IBM is likely to be less when the level of interfunctional communication is high. Consequently, employees are less likely to develop deep emotion connections with the brand and support the organizations' brand-building efforts beyond their job context. In general, we predict that interfunctional communication 
can reduce the positive effects of IBM on extra-role EBBB when the IBM level is relatively low.

On the other hand, we argue that interfunctional communication coupled with wellestablished IBM improves extra-role EBBB. Well-established IBM allows organizations to deliver consistent information about the brand promise effectively (Papasolomou \& Vrontis, 2006; Punjaisri \& Wilson, 2011). As discussed earlier (hypothesis 2), although employees can develop a better understanding about the brand promise under this condition, highly effective IBM also creates a strong brand community within the organization, which prevents employees for seeking other positive ways to deliver the brand promise beyond their job context. As a result, highly effective IBM discourages extra-role EBBB. We now suggest that interfunctional communication can create an environment that helps to reverse these effects.

Due to cross-functional differences (Fisher et al., 1997; Rouziès et al., 2005), employees from different functional departments need to find different ways to deliver the brand promise that suit their specific functional department (human resources, marketing, product development, etc.). This means that employees from different departments have slightly different ideas about delivering the brand promise to the customers. Greater interfunctional communication creates an environment in which employees from different departments can exchange ideas (Miles \& Mangold, 2005). We argue that this can help individual employees to start directing their attention toward exploring new and positive ways to participate in organizations' brand-building efforts. This is because individual employees discover that their colleagues (from different departments) all deliver the brand promise to the customers differently for the good of the organizations' brand. As a result, they are more likely to acknowledge that it is acceptable to use different and positive ways to support the organizations' brand-building efforts within the brand community (Morhart et al., 
2009). Therefore, effective IBM is less likely to discourage extra-role EBBB, when the level of interfunctional communication is high.

Hypothesis 5: The inverted U-shaped effects of internal branding mechanisms on extra-role EBBB are weaker (flatter) when interfunctional communication is strong.

\section{Research Method}

\subsection{Research Context}

The unit of analysis for this study is the organization, and we drew our data from a cross-sectional questionnaire survey of nonprofit organizations in the UK, which offer an appropriate research context for two reasons. First, internal branding is an important topic in nonprofit brand research in the UK (e.g. Hankinson, 2004; Liu et al., 2015). A marketing manager from an Art/Culture nonprofit made the following statement during our pilot study:

"[...] unlike commercial businesses, the public will question the charitable nature of our business, if we spend too much on [external] marketing activities to build the reputation of our brand. I personally find that internal branding can help us to communicate about our brand in a cost-efficient manner, so we can devote more resources toward our charitable activities."

This quotation indicates that internal branding is a useful way to establish the brand promise without consuming significant resources, which can then support nonprofit organizations' mission-related activities. Furthermore, prior studies reported that nonprofit organizations pursue brand orientation (e.g. Hankinson, 2001) or IBM (e.g. Laidler-Kylander \& Simonin, 2009) to build their employees’ understanding about the brand promise from the organizational perspective. Prior studies also suggest that nonprofit employees (and volunteers) who possess knowledge about the organizations' brand promise are more likely to delivery brand promise (e.g. Hankinson, 2004; Liu et al., 2015). Second, due to the intense competition and decline in government funding, UK-based nonprofit organizations of all sizes need to adopt various methods to raise funds themselves in order to support their social missions (Hankinson, 2001; Liu, Eng, \& Sekhon, 2013). Brand-building efforts often form 
the centerpiece of UK-based nonprofit organizations’ fundraising strategy to attract corporate donors and volunteers (Hankinson, 2001, 2002). A communication manager from an environment-related nonprofit organization indicated:

“Although we aren't a large organization, we find that communication between different departments and branches really helps us to get our message [brand promise] across [...], especially as we have both a commercial and charitable side that involves various small groups of full-time staff and lots of volunteers.

In line with prior studies, this quotation stresses the important role of communication between employees from different functional units (such as commercial vs. charitable side of business operation) toward nonprofit organizations' brand-building efforts (e.g. Hankinson, 2002; Liu et al., 2013).

\subsection{Research Design}

We adopted the measurement (five-point Likert scale) for our variables from existing studies (see Appendix 1). We tested the questionnaire items on a sample of 10 nonprofit organizations' senior executives. We used their responses to revise the questionnaire and so enhance the clarity and relevance of our research context. To measure brand orientation, we adopted items from Ewing and Napoli (2005) to assess the extent to which organizations engage in orchestration, interaction, and affect activities. We measured IBM using items from Punjaisri and Wilson (2011) to assess the internal communication tools (i.e. group meetings, briefings) and training programs (i.e. orientation, training) related to internal branding activities. We adapted items from Morhart et al. (2009) to assess both in-and extra-role brand-building behaviors. For interfunctional communication, we adapted the items from Hulland et al. (2012) to assess the quality and effectiveness of the communication among staff from different departments.

We consider several control variables. Researchers have discussed the effect of organization size on branding activities widely in the literature (e.g. Baker et al., 2014; Ewing 
\& Napoli, 2005). To measure organization size, we use a five-point scale to measure annual revenue $(1$ = below $£ 25,000 ; 2=£ 25,001-£ 100,000 ; 3=£ 101,000-£ 500,000 ; 5=$ above $£ 501,001)$. According to Zahra, Neubaum, and El-Hagrassey (2003), this format counteracts the respondents' potential unwillingness to disclose financial information. We also control for sector effect because this may influence brand communication and employees' attitudes toward the brand (Ewing \& Napoli, 2005). We chose "other charitable purpose sector" as the benchmark group (code $=0$ ) and coded six other sector dummies: education, health/recreation, general charitable care, housing/accommodation, art/culture, and environment (code $=1)$.

Finally, prior researches suggest that existing brand knowledge (either positive or negative) within the organization can also influence internal branding effectiveness (Burmann \& Zeplin, 2005; Punjaisri \& Wilson, 2011). Therefore, we control for brand distinctiveness, which assesses the extent to which organizational members already recognize the distinct brand promise. We develop a single-item scale to measure brand distinctiveness because, when phenomena represent concrete and singular objects, it is easy to capture them using a single-item scale (Bergkvist \& Rossiter, 2007). We presented this item to nonprofit organizations representatives during our pilot phase and incorporated their resulting feedback into the revised version. The final statement for this measurement is - "our brand is differentiated from the brands of our competitors.”

Charity Commission UK registers and regulates nonprofit organizations in England and Wales. Anyone can use the Commission's website to identify nonprofit organizations that meet specific criteria (Charity Commision UK, 2016). We used this website function randomly to identify 1500 nonprofit organizations that raise funds from diverse sources. We wrote to the CEO or managing director of each nonprofit organization and asked them to respond to our questionnaires on behalf of their organization. Through sending out two waves 
of surveys, we obtained 314 usable questionnaires (response rate $=20.9 \%$ ). To estimate the non-response bias, we used the t-test to compare all of the items we received from the first and second wave surveys. Furthermore, we used the t-test to compare all of the items received from the early and late responses to each wave of surveys (the $1^{\text {st }}$ and $4^{\text {th }}$ quartiles), respectively. The results indicate that the responses in both studies were approximately the same, so the probability of non-response bias is minimal (Armstrong \& Overton, 1977).

\subsection{Measurement Quality}

To assess the quality of our measurement, we applied an overall confirmatory factor analysis (CFA), where we load each measurement item only onto its latent construct and correlate all latent constructs. We use the Maximum Likelihood (ML) estimate approach to run CFA on SPSS AMOS. Following Hair, Black, Babin, and Anderson (2010), we assess the fit indexes from the different classes: chi-square $\left(X^{2}\right)$, degree of freedom $(d f)$, comparative fit index (CFI), normed fit index (NFI), goodness of fit index (GFI), and root mean square error of approximation (RMSEA). The key fit indexes $\left(X^{2}=351.259 ; d f=206 ; X^{2} / d f=1.705 ; \mathrm{p}\right.$ $=.000, \mathrm{CFI}=.971 ; \mathrm{NFI}=.934 ; \mathrm{GFI}=.916 ; \mathrm{RMSEA}=.057)$ suggest an acceptable model fit. The composite reliability (CR) and average variance extracted (AVE) of each construct exceeded the .70 and .50 thresholds, so the convergent validity appears to be adequate (see

Table 1). The square root value of the AVE for each construct is much higher than its shared correlation with other constructs, which supports discriminant validity (see Table 1). Together, the results indicate that our measurements possess adequate reality and construct validity.

“Insert Table 1 Here”

We followed Podsakoff, MacKenzie, Lee, and Podsakoff (2003) in using multiple statistical remedies to assess the potential common method bias. First, we performed 
Harman’s single-factor test. The results indicate that a single factor did not explain the majority of the variance (the highest single variance extracted was 43.93\%). Second, we use the CFA marker variable techniques. We use “co-worker trust” (three items; a simple item: “our employees are able to admit mistakes to co-workers”) adapted from Dunn, Ruedy, and Schweitzer (2012) as the marker variable. We first squared the factor loadings connected to the marker variables. We found that the highest value accounts for only $32.83 \%$ of the variance (less than the majority). Second, we compared the factor correlation related to the variables between the CFA model with and without market variables. We found that the differences between the factor correlations are not significant. Both results suggest that common method bias was unlikely to affect this study.

\section{Findings}

\subsection{Hypotheses Test}

We use multiple regression analysis to test the hypotheses (Haans, Pieters, \& He, 2015; Hair et al., 2010). The results shown in Model 1 suggest a positive relationship between IBM and in-role $\operatorname{EBBB}(\beta=.367, \mathrm{p}<.001)$, which confirms hypothesis 1 . Model 2 shows that the relationship between IBM and extra-role EBBB is positive and significant ( $\beta=.355, \mathrm{p}$ $<.001$ ), while that between the quadratic term of IBM and extra-role EBBB is negative and significant $(\beta=-.085, \mathrm{p}<.010)$. Thus, we confirm hypothesis 2 , which suggests that IBM has an inverted U-shaped effect on extra-role EBBB. We plot this inverted-U shaped relationship in Figure 2a. The results from Model 3 confirm our prediction by showing that orchestration $(\beta=.203, \mathrm{p}<.001)$, interaction $(\beta=.402, \mathrm{p}<.001)$, and affect $(\beta=.321, \mathrm{p}<.001)$ have positive and significant relationships with IBM, thus confirming hypothesis 3.

“Insert Table 2 about Here”

"Insert Figure 2 about Here” 
For moderation effects, we estimate a regression model (Model 4) and find that the effect of the interaction term of IBM and interfunctional communication on in-role EBBB is non-significant $(\beta=-.053, p>.100)$. Thus, we reject hypothesis 4 , which predicts that interfunctional communication positively moderates the relationship between IBM and inrole EBBB. Hypothesis 5 predicts that the inverted U-shaped effect of IBM on extra-role $\mathrm{EBBB}$ is weaker (flatter) when interfunctional communication is strong. We estimate a regression model (Model 5). The result suggests that the effect of the interaction term of the quadratic term of IBM and interfunctional communication on extra-role EBBB is significant $(\beta=.047, \mathrm{p}<.100)$. We plot the moderation relationship in Figure $2 \mathrm{~b}$. Surprisingly, we find a shape-flip phenomenon in our graphical representation. This means that the inverted Ushaped relationship between IBM and extra-role EBBB is significantly flattening and flipping to a U-shaped relationship, due to the strong moderating effect of interfunctional communication. Haans et al. (2015) describe this kind of curve changing phenomenon as “shape-flip”. For greater clarity, we plot the relationship between IBM and extra-role EBBB for both low- and high-level interfunctional communication (see Figure 2c). Overall, we confirm hypothesis 6.

\subsection{Additional Studies}

We conduct additional tests to search for a possible mediation relationship. First, we investigate IBM as a mediator between brand orientation and in-role EBBB. Hayes (2013) suggests that the confirmation of the mediation relationship in our model rests on three conditions. In our earlier findings in Model 3, we confirmed the positive and significant relationship between brand orientation and IBM. Thus, this fulfills condition 1 . To fulfill condition 2, we estimate a new regression model (Model 6) and find the effect of IBM on inrole $\operatorname{EBBB}(\beta=.245, \mathrm{p}<.001)$, when accounting for the brand orientation effect. This result 
satisfies condition 2. Finally, we calculate the indirect effect using a bootstrap analysis with 10,000 samples. Our result suggests that all three indirect effects due to different brand orientation dimensions are significant, with a 95\% confidence interval that does not include zero. Thus, this fulfills condition 3. To summarize the above findings, we confirm this mediation relationship.

Second, we investigate IBM as mediator between brand orientation and extra-role EBBB. Since IBM and extra-role EBBB share a nonlinear relationship, we follow Hayes and Preacher (2010) in examining the nonlinear mediating relationship, who argue that the confirmation of a nonlinear mediating relationship requires three conditions. To meet condition 1, we must confirm the positive and significant relationship between brand orientation and IBM, which we did earlier (Model 3). In order to meet condition 2, we estimate Model 7 to confirm the significant effects of IBM $(\beta=.762, p<.001)$ and the quadratic term of IBM $(\beta=-.082, \mathrm{p}<.010)$ on extra-role EBBB, when accounting for brand orientation effect. To meet condition 3, we must ensure that the indirect effect is significant. We calculate the instantaneous indirect effect in relatively low $\left(25^{\text {th }}\right.$ percentiles $)$, relatively moderate $\left(50^{\text {th }}\right.$ percentiles) and relatively high $\left(75^{\text {th }}\right.$ percentiles) situations using a bootstrap analysis with 10,000 samples. Our results suggest that the instantaneous indirect effects of all three brand orientation dimensions are significant in all three percentiles, with a 95\% confidence interval that does not include zero. This satisfies condition 3. In general, we confirm this nonlinear mediating relationship.

Furthermore, to enhance the generalizability of our findings and gain a richer understanding of internal branding processes (Blumberg, Cooper, \& Schindler, 2014), we conduct 12 post-hoc interviews with marketing (or communication) managers from different nonprofit organizations. We invited the interviewees to describe their experience regarding internal branding without a prior knowledge of our survey findings. This included the 
interviewees’ expectations, critical events throughout the practices internal branding, and their personal evaluation of the factors and boundary conditions that affect internal branding processes. These interviews helped us to triangulate our findings from the survey and offered deeper insights regarding internal branding. We discuss our survey results together with our post-hoc interview findings below.

\section{Discussion and Conclusion}

\subsection{Academic Implications}

First, brand orientation (King et al., 2013; Urde et al., 2013) and IBM (Mitchell, 2002; Vallaster \& de Chernatony, 2006) represent two important internal branding approaches, but no empirical studies have yet tested the association between these two phenomena. Our research is the first to use empirical data to examine and confirm this relationship. Furthermore, a health/recreation nonprofit organization brand manager noted, during a posthoc interview:

"During our re-branding efforts, we focus on gathering feedback from our stakeholders [i.e. employees] and understanding how they feel about our new logo and new brand promise. [...]. We use these insights to design our [brand] communication strategies for our donors [external], volunteers and employees [internal].”

A marketing and communication manager from a General Charitable Care nonprofit organization expressed a different view:

"We ensure our [brand] messages are consistent across every communication channel we use. [...]. For internal [brand] communication, we work with HR to integrate these [brand] messages into the staff training manuals and orientation package.”

According to these post-hoc interviews, the development of effective internal communication tools and training programs requires: 1) the organizations' brand promise information is consistent across the various communication channels during dissemination; and 2) the organizations' development of the brand promise must incorporate the different stakeholders' 
(including the employees) points of view and feelings about the organization. These findings are in line with our theoretical logic regarding the relationship between brand orientation and IBM. In general, we contribute to the internal branding literature (e.g. Hankinson, 2001; Mitchell, 2002) by suggesting that organizations’ investment in establishing their brand orientation can facilitate the development of outgoing systematic communication tools to help their employees to articulate the organizational value and understand their roles within the organizations.

Second, our survey results show that a positive and linear relationship exists between IBM and in-role EBBB, as well as an inverted-U shaped relationship between IBM and extrarole EBBB. During a post-hoc interview, the head of digital \& communications at an education nonprofit organization stated:

"We constantly communicate our values [reflected in our brand] through our newsletter and meetings [...], as well as our training programs. [...]. I think that is why the people [staff and volunteers] in our organization accept and act consistently with our [brand] value.”

This quotation provides further evidence that internal brand communication activities enable organizations to build their employees' understanding of the brand promise, which in turn motivates employees to behave consistently with the brand promise when interacting with others. This finding echoes our survey results about the positive relationship between IBM and in-role EBBB. On the other hand, a communication director from an art/culture nonprofit organization recalled that:

"I believe that training and internal communication [about our brand promise] can encourage our staff to support our brand in any way possible, even though we don't require them to do so [beyond their assigned job/tasks]. [...]. However, I am also skeptical about whether this kind of communication [IBM] helps [to promote extrarole EBBB], when it is emphasized too excessively. My experience tells me that this is not always the case. An excessive focus on brand communication [IBM] can have the opposite effect [of promoting extra-role EBBB], because the staff may feel that they should not do anything beyond what we've asked them to do." 
The above comments imply that, when organizations focus excessively on their IBM, this tends to create an atmosphere within the organization, which pressures the employees to behave in a certain way regarding delivering the brand promise. Such excessive focus also deters the employees from going beyond their prescribed role to interact with customers for the good of the brand. Our post-hoc interview results are consistent with our survey results and our theoretical logic in explaining the inverted-U shaped relationship between IBM and extra-role EBBB. Both findings enrich the internal branding literature, that does not differentiate between the two types of EBBB (Baumgarth \& Schmidt, 2010; Punjaisri \& Wilson, 2007) by distinguishing the effect of IBM on in- and extra-role EBBB. This distinction is important because in- and extra-role EBBB capture two distinct ways in which employees deliver the brand promise to the customers (Morhart et al., 2009). Our theoretical logic and empirical findings indicate that researchers must differentiate between the different types of EBBB when studying internal branding.

Our study also confirms that IBM mediates the relationship between brand orientation and EBBB in both linear (in-role EBBB) and nonlinear (extra-role EBBB) situations. It further contributes to the internal branding literature that explores the direct association between brand orientation and EBBB (e.g. Baumgarth \& Schmidt, 2010; Hankinson, 2002) by suggesting that brand orientation does not automatically lead to employees' brandbuilding behaviors. Instead, it provides a context for facilitating IBM development, which in turn affects EBBB. In doing so, this finding offers a fresh theoretical angle for examining internal branding. Using attention-based view logic (Barnett, 2008; Ocasio, 1997), we conclude that internal branding is the process by which organizations regulate and distribute their employees’ attention to support the organizational brand-building efforts.

Our third contribution is to clarify the role of interfunctional communication in internal branding processes. Contrary to our prediction, we find that interfunctional 
communication has no significant impact on the IBM/in-role EBBB relationship. A housing/accommodation nonprofit organization’s marketing manager offers a possible explanation for this:

"[...] too much communication [between staff from different functional departments] within the organization can sometime undermine our internal branding efforts, especially when they [the staff] are unfamiliar with the brand [premise]. Speaking from my own experience during re-branding processes, we must always ensure that our new brand [premise] is not being misinterpreted or miscommunicated by our staff.”

This comment implies that greater interfunctional communication creates a work environment in which employees can express and share their personal views about the brand promise. This creates inconsistent information about the brand promise within the organization. Therefore, interfunctional communication can undermine the impact of IBM on in-role EBBB. We also find that the moderating effect of interfunctional communication on the relationship between IBM and extra-role EBBB is very strong and causes the inverted-U shaped curve to flatten significantly and change into a concave upward curve (Haans et al., 2015) (see Figure 2b). During a post-hoc interview, a communication manager from an environment nonprofit organization made the following suggestion that helps to explain the results:

“[...], our efforts to engage in internal communication [and staff training] and encourage them [the staff] to share what they learn about our brand [promises] may not yield a great benefit initially. [...], however, beyond a certain point, our staff start to come up with creative ideas regarding what they can do to help us to build a strong nonprofit brand and communicate it [the brand promise] to our stakeholders.

Greater interfunctional communication creates a work environment in which employees exchange their personal ideas about how to participate in the organizations' brand-building efforts in their own way. These actions help to enhance the effect of IBM on extra-role EBBB. However, when IBM is less established, they cannot disseminate the information about the brand promise effectively. Thus, the effect of IBM on extra-role EBBB is weak, even though interfunctional communication can help to enhance the effectiveness of information 
dissemination. On the other hand, when well-established IBM and greater interfunctional communication are both present, organizations become highly effective at communicating the brand promise to their employees. Therefore, IBM can facilitate extra-role EBBB at an accelerating rate - a concave upward curve, as in our findings (see Figure 2b and 2c). Together, these findings contribute to the internal branding literature by enriching our understanding of how the nature of the work environment affects internal branding (e.g. Punjaisri \& Wilson, 2011; Vallaster \& de Chernatony, 2006).

\subsection{Managerial Implications}

First, organizations can pursue internal branding by investing in brand orientation that provides a suitable context for guiding IBM establishment, which leads to EBBB. Furthermore, our analysis suggests that any dimension of brand orientation (orchestration, interaction, or affect) alone can facilitate IBM. For organizations that lack abundant resources, managers can concentrate their investment on developing only one dimension of brand orientation to support their internal branding.

Secondly, managers must be aware of the impact of IBM on different types of EBBB. To promote in-role EBBB, managers should support the full development of IBM. On the other hand, to promote extra-role EBBB, managers should be aware that the impact of IBM may diminish after a certain point. Third, effective interfunctional communication can create a favorable organizational environment that facilitates the positive effect of IBM on extrarole EBBB. As a result, managers should cultivate effective interfunctional communication within their organizations before investing in IBM development.

\subsection{Limitations and Future Research}


First, the use of a cross-sectional research design cannot formally test the causality, and reliance on self-reports runs the risk of common method bias (Hair et al., 2010). In future, researchers might employ longitudinal research designs and objective data to confirm causality, and a dyadic (or multi-level) dataset to eliminate common method bias. Second, we did not control for specific cultural factors that may potentially influence internal branding processes (Miles \& Mangold, 2005). Because brand orientation can be considered a cultural factor (Urde, 1999; Urde et al., 2013), we study its impact on internal branding processes. Furthermore, organizational culture varies more across industries than within them (e.g. Chatman \& Jehn, 1994). By controlling the sector dummies, we account for cultural factors' influence on internal branding. Nevertheless, further research might control other specific cultural factors (i.e. innovation culture) to enhance the findings' reliability. Third, we conducted our study in a single country (the UK) and a single industry (nonprofit organizations). Future research should replicate this study across multiple countries and industries to improve its generalizability.

Finally, there exist several further research avenues. For example, we find that interfunctional communication does not influence the relationship between IBM and in-role EBBB. Future studies may investigate the reasons behind this finding. Furthermore, we examine brand orientation as the antecedent of IBM. Future researchers may explore other potential antecedents of IBM such as brand legitimacy (Liu et al., 2013) and brand-specific leadership (Morhart et al., 2009), to add value to the internal branding literature. 


\section{Reference}

Armstrong, J.S., \& Overton, T.S. (1977). Estimating nonresponse bias in mail surveys. Journal of Marketing Research, 14(3), 396-402.

Baker, T.L., Rapp, A., Meyer, T., \& Mullins, R. (2014). The role of brand communications on front line service employee beliefs, behaviors, and performance. Journal of the Academy of Marketing Science, 42(6), 1-16.

Barnett, M.L. (2008). An attention-based view of real options reasoning. Academy of Management Review, 33(3), 606-628.

Bateman, T.S., \& Organ, D.W. (1983). Job satisfaction and the good soldier: The relationship between affect and employee “citizenship”. Academy of Management Journal, 26(4), 587-595.

Baumgarth, C., \& Schmidt, M. (2010). How strong is the business-to-business brand in the workforce? An empirically-tested model of ‘internal brand equity’in a business-tobusiness setting. Industrial Marketing Management, 39(8), 1250-1260.

Bergkvist, L., \& Rossiter, J.R. (2007). The predictive validity of multiple-item versus singleitem measures of the same constructs. Journal of Marketing Research, 44(2), 175184.

Blumberg, B., Cooper, D.R., \& Schindler, P.S. (2014). Business research methods, 4th European Edition. London, UK: McGraw-Hill Education.

Burmann, C., \& Zeplin, S. (2005). Building brand commitment: A behavioural approach to internal brand management. Journal of Brand Management, 12(4), 279-300.

Charity Commision UK. (2016). Search for charities by their registered details

Chatman, J.A., \& Jehn, K.A. (1994). Assessing the relationship between industry characteristics and organizational culture: How different can you be? Academy of Management Journal, 37(3), 522-553. 
Dunn, J., Ruedy, N.E., \& Schweitzer, M.E. (2012). It hurts both ways: How social comparisons harm affective and cognitive trust. Organizational Behavior and Human Decision Processes, 117(1), 2-14.

Escalas, J.E., \& Bettman, J.R. (2005). Self-construal, reference groups, and brand meaning. Journal of Consumer Research, 32(3), 378-389.

Ewing, M.T., \& Napoli, J. (2005). Developing and validating a multidimensional nonprofit brand orientation scale. Journal of Business Research, 58(6), 841-853.

Fisher, R.J., Maltz, E., \& Jaworski, B.J. (1997). Enhancing communication between marketing and engineering: The moderating role of relative functional identification. Journal of Marketing, 61(3), 54-70.

Haans, R.F.J., Pieters, C., \& He, Z.-L. (2015). Thinking about U: Theorizing and testing Uand inverted U-shaped relationships in strategy research. Strategic Management Journal, 37(7), 1177-1195.

Hair, J.F., Black, W., C., Babin, B.J., \& Anderson, R.E. (2010). Multivariate data analysis (7th Edition). Upper Saddle River, NJ.: Prentice Hall.

Hankinson, P. (2001). Brand orientation in the Top 500 fundraising charities in the UK. Journal of Product \& Brand Management, 10(6), 346-360.

Hankinson, P. (2002). The impact of brand orientation on managerial practice: A quantitative study of the UK's top 500 fundraising managers. International Journal of Nonprofit and Voluntary Sector Marketing, 7(1), 30-44.

Hankinson, P. (2004). The internal brand in leading UK charities. Journal of Product \& Brand Management, 13(2), 84-93.

Hayes, A.F. (2013). Introduction to mediation, moderation, and conditional process analysis: A regression-based approach. New York: Guilford Press. 
Hayes, A.F., \& Preacher, K.J. (2010). Quantifying and testing indirect effects in simple mediation models when the constituent paths are nonlinear. Multivariate Behavioral Research, 45(4), 627-660.

Hickman, T., \& Ward, J. (2007). The dark side of brand community: Inter-group stereotyping, trash talk, and schadenfreude. Advances in Consumer Research, 34.

Hulland, J., Nenkov, G.Y., \& Barclay, D.W. (2012). Perceived marketing-sales relationship effectiveness: A matter of justice. Journal of the Academy of Marketing Science, 40(3), 450-467.

King, C., \& Grace, D. (2010). Building and measuring employee-based brand equity. European Journal of Marketing, 44(8), 938-971.

King, C., So, K.K.F., \& Grace, D. (2013). The influence of service brand orientation on hotel employees’ attitude and behaviors in China. International Journal of Hospitality Management, 34(1), 172-180.

Laidler-Kylander, N., \& Simonin, B. (2009). How international nonprofits build brand equity. International Journal of Nonprofit and Voluntary Sector Marketing, 14(1), 57-69.

Liu, G., Chapleo, C., Ko, W.W., \& Ngugi, I.K. (2015). The role of internal branding in nonprofit brand management: An empirical investigation. Nonprofit and Voluntary Sector Quarterly, 44(2), 319-339.

Liu, G., Eng, T.Y., \& Sekhon, Y.K. (2013). Managing branding legitimacy: A study of charity retail sector. Nonprofit and Voluntary Sector Quarterly, doi: 10.1177/0899764012474722.

McQuillan, P., \& Oddie, H. (2011). Internal branding benchmarking study - 2010. Toronto: Canadian Marketing Association.

Miles, S.J., \& Mangold, W.G. (2004). A conceptualization of the employee branding process. Journal of Relationship Marketing, 3(2-3), 65-87. 
Miles, S.J., \& Mangold, W.G. (2005). Positioning Southwest Airlines through employee branding. Business Horizons, 48(6), 535-545.

Mitchell, C. (2002). Selling the brand inside. Harvard Business Review, 80(1), 99-105.

Morhart, F.M., Herzog, W., \& Tomczak, T. (2009). Brand-specific leadership: Turning employees into brand champions. Journal of Marketing, 73(5), 122-142.

Muniz, A.M., \& Schau, H.J. (2005). Religiosity in the abandoned Apple Newton brand community. Journal of Consumer Research, 31(4), 737-747.

Napoli, J. (2006). The impact of nonprofit brand orientation on organisational performance. Journal of Marketing Management, 22(7), 673-694.

Ocasio, W. (1997). Towards an attention-based view of the firm. Strategic Management Journal, 18(1), 187-206.

Papasolomou, I., \& Vrontis, D. (2006). Using internal marketing to ignite the corporate brand: The case of the UK retail bank industry. Journal of Brand Management, 14(1), 177-195.

Podsakoff, P.M., MacKenzie, S.B., Lee, J.Y., \& Podsakoff, N.P. (2003). Common method biases in behavioral research: a critical review of the literature and recommended remedies. Journal of Applied Psychology, 88(5), 879-903.

Punjaisri, K., Evanschitzky, H., \& Wilson, A. (2009). Internal branding: An enabler of employees' brand-supporting behaviours. Journal of Service Management, 20(2), 209226.

Punjaisri, K., \& Wilson, A. (2007). The role of internal branding in the delivery of employee brand promise. Journal of Brand Management, 15(1), 57-70.

Punjaisri, K., \& Wilson, A. (2011). Internal branding process: Key mechanisms, outcomes and moderating factors. European Journal of Marketing, 45(10), 1521-1537. 
Rouziès, D., Anderson, E., Kohli, A.K., Michaels, R.E., Weitz, B.A., \& Zoltners, A.A. (2005). Sales and marketing integration: A proposed framework. Journal of Personal Selling and Sales Management, 25(2), 113-122.

Spector, R., \& McCarthy, P.D. (2012). The Nordstrom way to customer service excellence: The handbook for becoming the" Nordstrom" of your industry. Hoboken, New Jersey: John Wiley \& Sons.

Urde, M. (1999). Brand orientation: A mindset for building brands into strategic resources. Journal of Marketing Management, 15(3), 117-133.

Urde, M., Baumgarth, C., \& Merrilees, B. (2013). Brand orientation and market orientationFrom alternatives to synergy. Journal of Business Research, 66(1), 13-20.

Vallaster, C., \& de Chernatony, L. (2006). Internal brand building and structuration: The role of leadership. European Journal of Marketing, 40(8), 761-784.

Zahra, S.A., Neubaum, D.O., \& El-Hagrassey, G.M. (2003). Competitive analysis and new venture performance: Understanding the impact of strategic uncertainty and venture origin. Entrepreneurship Theory and Practice, 27(1), 1-28. 
Figure 1: Theoretical Framework

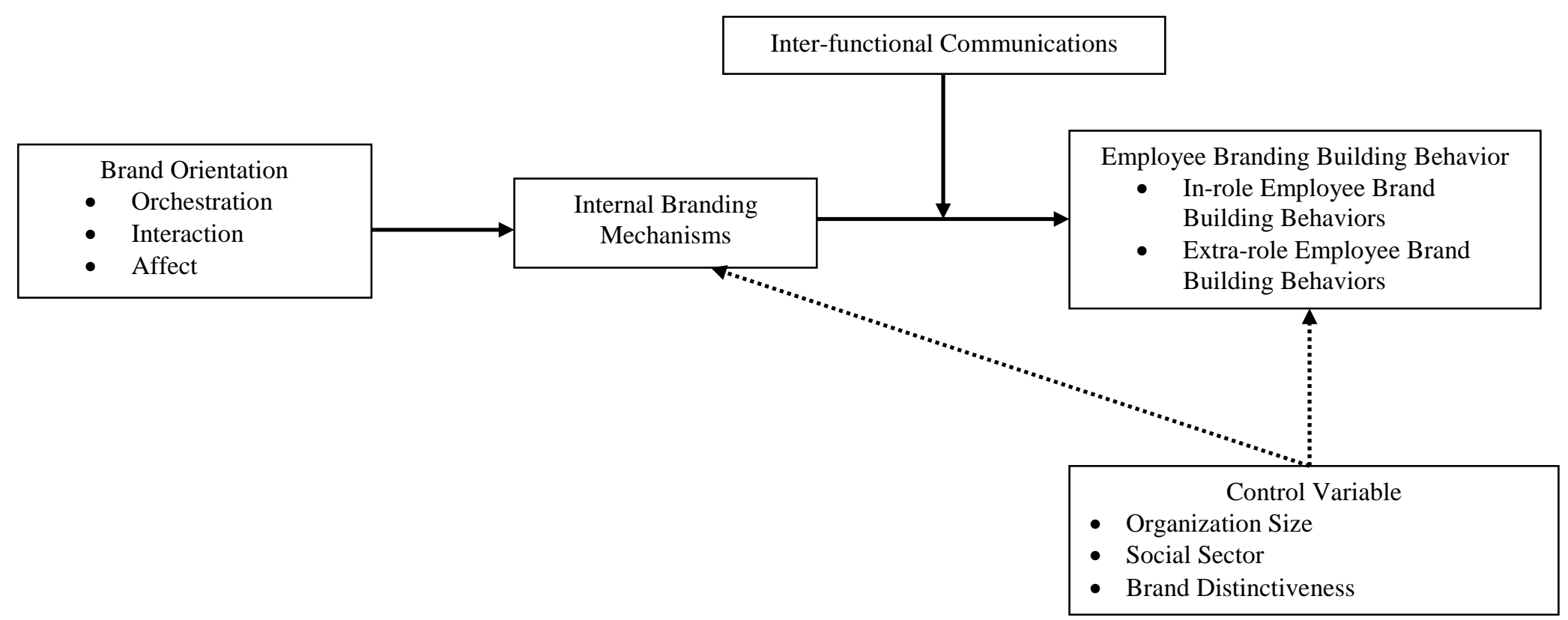

Notes:

Statistical Control ............ 
Table 1: Descriptive Statistics

\begin{tabular}{|c|c|c|c|c|c|c|c|c|c|c|c|c|c|c|c|}
\hline & 1 & 2 & 3 & 4 & 5 & 6 & 7 & 8 & 9 & 10 & 11 & 12 & 13 & 14 & 15 \\
\hline 1. Organization Size & $\begin{array}{ll}-- \\
-1\end{array}$ & & & & & & & & & & & & & & \\
\hline 2. Education & .053 & --- & & & & & & & & & & & & & \\
\hline 3. Health/Recreation & -.005 & $-.162 *$ & --- & & & & & & & & & & & & \\
\hline 4. General Charitable Care & $.126 *$ & $-.207^{*}$ & $-.237 *$ & --- & & & & & & & & & & & \\
\hline 5. Housing/Accommodation & .044 & -.096 & -.109 & $-.140^{*}$ & --- & & & & & & & & & & \\
\hline 6. Art/Culture & $-.141^{*}$ & $-.136^{*}$ & $-.155^{*}$ & $-.198^{*}$ & -.091 & --- & & & & & & & & & \\
\hline 7. Environment & .008 & -.072 & -.082 & -.105 & -.048 & -.069 & --- & & & & & & & & \\
\hline 8. Brand Distinctiveness & $.147 *$ & .012 & -.032 & .031 & -.03 & .058 & .016 & --- & & & & & & & \\
\hline 9. Brand Orientation: Orchestration & .102 & -.033 & .054 & -.019 & .028 & -.002 & .040 & $.457 *$ & .779 & & & & & & \\
\hline 10. Brand Orientation: Interaction & $.112 *$ & -.036 & -.046 & .078 & .075 & $-.131 *$ & .034 & $.311 *$ & $.462 *$ & .722 & & & & & \\
\hline 11. Brand Orientation: Affect & .046 & .089 & .017 & .016 & -.073 & -.066 & .048 & $.365 *$ & $.454 *$ & $.509 *$ & .908 & & & & \\
\hline 12. Internal Branding Mechanisms & .064 & .007 & .032 & -.019 & .037 & -.047 & .016 & $.391 *$ & $.521 *$ & $.577 *$ & $.586^{*}$ & .801 & & & \\
\hline 13. In-role Employee Brand-building Behavior & $.158 *$ & .055 & .101 & .005 & -.027 & -.098 & -.038 & $.421 *$ & $.399 *$ & $.454 *$ & $.435^{*}$ & $.536 *$ & .841 & & \\
\hline 14. Extra-role Employee Brand-building Behavior & .091 & .082 & .040 & -.068 & -.029 & -.053 & -.039 & $.378 *$ & $.441^{*}$ & $.520 *$ & $.456^{*}$ & $.567 *$ & $.612^{*}$ & .788 & \\
\hline 15. Inter-functional Communications & .105 & .043 & -.020 & .026 & .020 & -.097 & -.059 & $.287 *$ & $.393 *$ & $.389 *$ & $.253^{*}$ & $.356 *$ & $.437 *$ & $.471^{*}$ & .869 \\
\hline Mean & 3.051 & .124 & .156 & .232 & .061 & .115 & .035 & 3.914 & 3.986 & 4.172 & 3.533 & 3.476 & 3.983 & 4.119 & 3.928 \\
\hline Standard Deviation & .913 & .330 & .363 & .423 & .239 & .319 & .184 & 1.055 & .923 & .725 & .944 & .968 & .827 & .807 & .940 \\
\hline Composite Reliability & --- & --- & --- & --- & --- & --- & --- & --- & .821 & .766 & .904 & .926 & .878 & .766 & .902 \\
\hline Average Variance Extracted & --- & --- & --- & --- & --- & --- & --- & --- & .607 & .522 & .824 & .641 & .707 & .621 & .755 \\
\hline
\end{tabular}

Notes:

${ }^{*} \mathrm{p}<.005$; Sample: $\mathrm{n}=314$

Average Variance Extracted (AVE) square roots are show in bold on the correlation matrix diagonal 
Table 2: Regression Results

\begin{tabular}{|c|c|c|c|c|c|c|c|}
\hline & Model 1 & Model 2 & Model 3 & Model 4 & Model 5 & Model 6 & Model 7 \\
\hline Outcomes: & In-role EBBB & Extra-role EBBB & IBM & In-role EBBB & Extra-role EBBB & In-role EBBB & Extra-role EBBB \\
\hline \multicolumn{8}{|l|}{ Control: } \\
\hline Organizational Size & $.077(1.796) \dagger$ & $.029(.702)$ & $-.015(-.340)$ & $.064(1.570)$ & $.017(.460)$ & $.071(1.680) \dagger$ & $.018(.459)$ \\
\hline Education & $.106(.824)$ & $.069(.551)$ & $-.017(-.126)$ & $.091(.728)$ & $.066(.569)$ & $.116(.906)$ & $.098(.815)$ \\
\hline Health/Recreation & (193(1.618) & $-.019(-.168)$ & $.067(.535)$ & $.224(1.950) \dagger$ & $.025(.239)$ & .214(1.810)† & $.012(.112)$ \\
\hline General Care & $.003(.028)$ & $-.158(-1.532)$ & $-.087(-.773)$ & $.024(.232)$ & $-.125(-1.313)$ & $-.012(-.115)$ & $-.178(-1.802) \dagger$ \\
\hline Housing/Accommodation & $-.118(-.696)$ & $-.229(-1.401)$ & $.128(.715)$ & $-.102(-.627)$ & $-.194(-1.280)$ & $-.122(-.726)$ & $-.250(-1.592)$ \\
\hline Art/Culture & $-.172(-1.293)$ & $-.166(-1.295)$ & $.008(.057)$ & $-.102(-.788)$ & $-.048(-.397)$ & $-.117(-.885)$ & $-.087(-.701)$ \\
\hline Environment & $-.205(-.958)$ & $-.319(-1.547)$ & $-.101(-.451)$ & $-.134(-.649)$ & $-.216(-1.127)$ & $-.233(-1.108)$ & $-.353(-1.788) \dagger$ \\
\hline Brand Distinctiveness & $.193(4.879)^{* * *}$ & $.144(3.795)^{* * *}$ & $.091(2.086)^{*}$ & $.159(4.128)^{* * *}$ & $.097(2.717)^{* *}$ & $.161(3.915)^{* * *}$ & $.099(2.571)^{*}$ \\
\hline \multicolumn{8}{|l|}{ Mean Effects: } \\
\hline Brand Orientation: Orchestration & & & $.203(3.783)^{* * *}$ & & & $.030(.582)$ & .062(1.282) \\
\hline Brand Orientation: Interaction & & & $.402(5.903)^{* * *}$ & & & $.187(2.762)^{* *}$ & $.287(4.526)^{* * *}$ \\
\hline Brand Orientation: Affect & & & $.321(6.135)^{* * *}$ & & & $.071(1.362)$ & $.058(1.184)$ \\
\hline Internal Branding Mechanisms (IBM) & $.367(8.628)^{* * *}$ & $.355(7.910)^{* * *}$ & & $.306(7.186)^{* * *}$ & $.292(6.232)^{* * *}$ & $.245(4.540)^{* * *}$ & $.762(4.094)^{* * *}$ \\
\hline IBM Squared & & $-.085(-2.932)^{* *}$ & & & $-.023(-.724)$ & & $-.082(-2.927)^{* *}$ \\
\hline Inter-functional Communications (IFC) & & & & $.187(4.218)^{* * *}$ & $.143(3.000)^{* *}$ & & \\
\hline \multicolumn{8}{|l|}{ Interaction Effects: } \\
\hline IBM $x$ IFC & & & & $-.053(-1.619)$ & $-.069(-1.279)$ & & \\
\hline IBM Squared x IFC & & & & & $.047(1.724) \dagger$ & & \\
\hline Constant & $2.987(15.241)^{* * *}$ & $3.623(18.963)^{* * *}$ & $-.447(-1.615)$ & $3.153(16.487)^{* * *}$ & $3.782(21.197)^{* * *}$ & $1.118(4.283)^{* * *}$ & $.511(1.470)$ \\
\hline \multicolumn{8}{|l|}{ Model Statistics } \\
\hline F-Value & 19.593 & 19.005 & 27.253 & 19.766 & 21.378 & 16.385 & 18.507 \\
\hline P-Value & .000 & .000 & .000 & .000 & .000 & .000 & .000 \\
\hline R-Square & .367 & .385 & .498 & .397 & .458 & .395 & .445 \\
\hline
\end{tabular}

Note:

Unstandardized Coefficients are reported with t-value in parathions

Employee Brand-Building Behavior $=$ EBBB 
Figure 2: Graphical Representation

a. Curvilinear Relationship

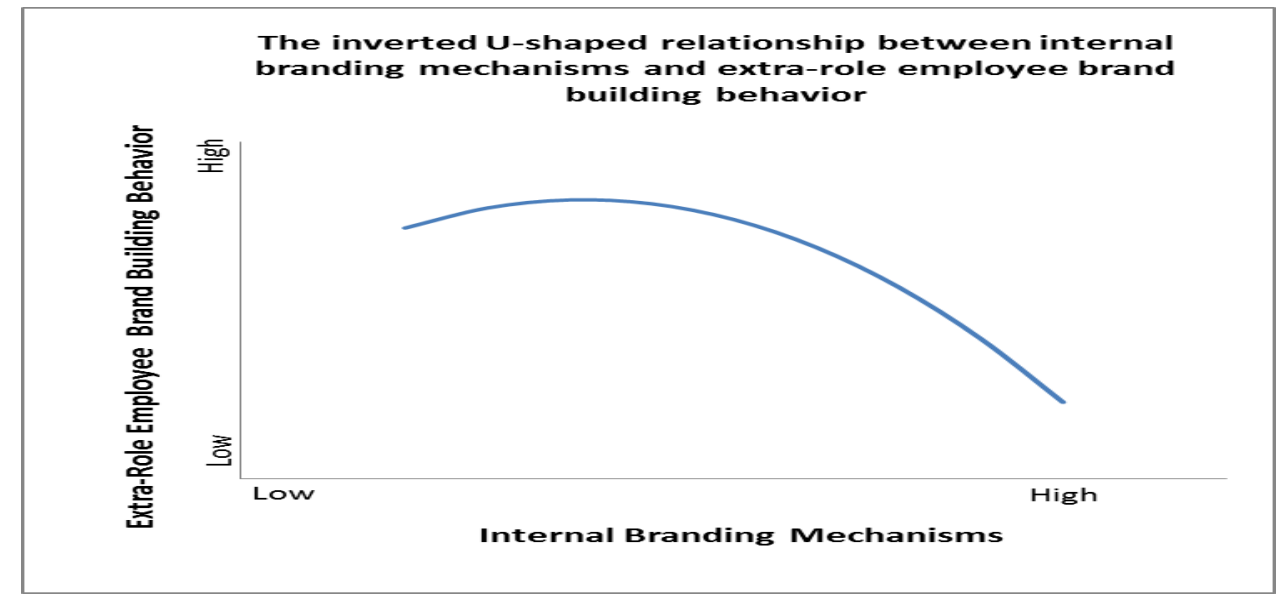

b. Shape-Flip Phenomenon

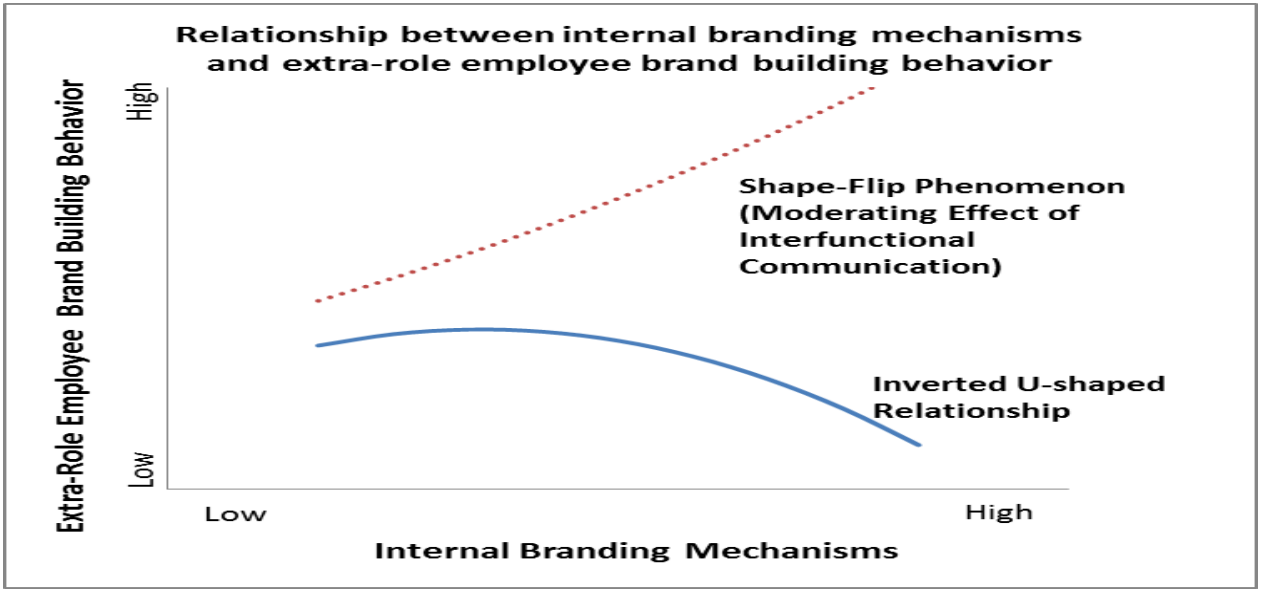

c. Moderating Effect

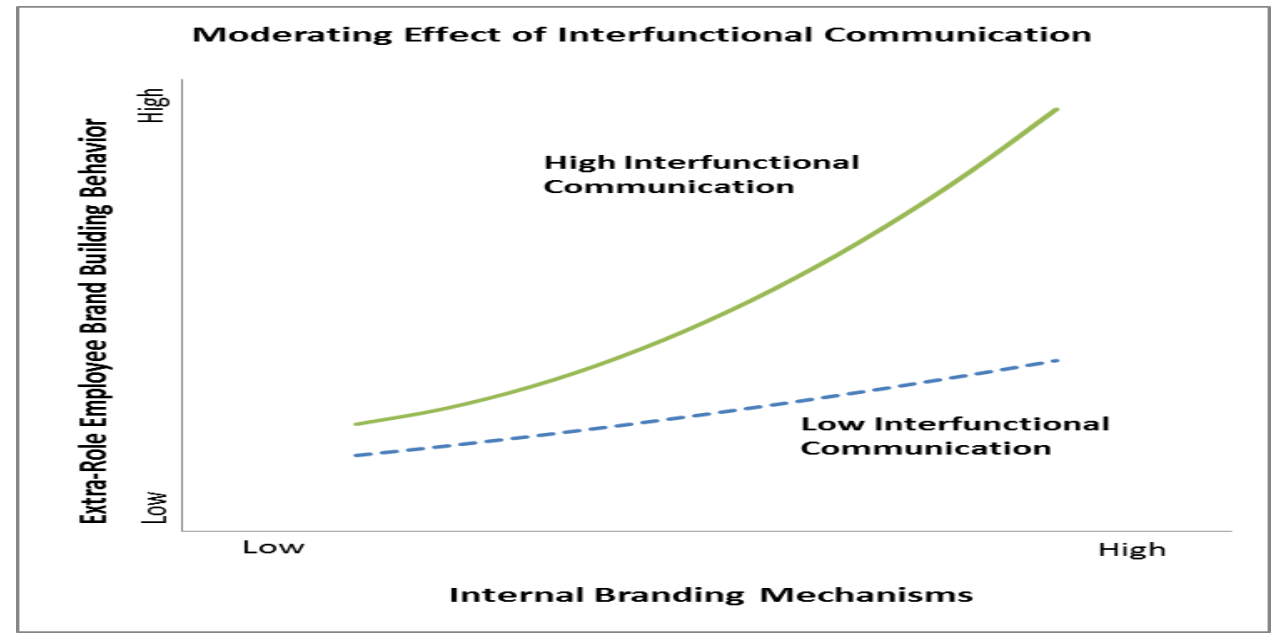


--- Item delate due to low fit 